\title{
USO DE MARCADORES MOLECULARES NA ANÁLISE DA VARIABILIDADE GENÉTICA EM ACEROLA (Malpighia emarginata D.C.) ${ }^{1}$
}

\author{
MARIA FERNANDA SPEGIORIN SALLA ${ }^{2}$, CLAUDETE DE FÁTIMA RUAS ${ }^{3}$, \\ PAULO MAURÍCIO RUAS ${ }^{4}$ E VALÉRIA CARPENTIERI-PÍPOLO 5
}

\begin{abstract}
RESUMO - A acerola (Malpighia emarginata) é uma frutífera tropical encontrada nativa na América Central e no Norte da América do Sul, sendo de grande importância econômica e social devido ao seu alto conteúdo de vitamina C (ácido ascórbico). Pomares de acerola têm sido preferencialmente estabelecidos por métodos de propagação vegetiva. No entanto, a propagação sexuada por sementes é igualmente utilizada e permite revelar um alto grau de polimorfismo na cultura, possibilitando a identificação de genótipos portadores de características de interesse agronômico. Vinte e quatro acessos de acerola, pertencentes ao Banco Ativo de Germoplasma da Universidade Estadual de Londrina, foram analisados, usando marcadores RAPD (Random amplified Polymorphic DNA) e obtidos com iniciadores (primers) de seqüência simples repetidas (SSRs). Um total de 164 e 73 marcadores foram obtidos com primers de RAPD e SSR, respectivamente. Os marcadores obtidos foram analisados, usando o método de agrupamentos UPGMA. A análise comparativa dos dendrogramas gerados com os primers de RAPD e com os primers SSR mostrou que, enquanto alguns acessos se associaram em grupos diferentes, outros apresentaram a mesma associação. Entretanto, maior polimorfismo entre acessos foi detectado com os primers de RAPD. A análise dos resultados revelou a alta variabilidade contida na coleção, permitindo associar o grau de similaridade genética, obtido por marcadores de DNA, com caracteres morfológicos compartilhados entre os acessos.
\end{abstract}

Termos para indexação: Acerola, Malpighia emarginata, marcadores RAPD e SSR, variabilidade genética.

\section{THE USE OF MOLECULAR MARKERS IN THE GENETIC VARIABILITY ANALYSIS OF ACEROLA (Malphighia emarginata)}

\begin{abstract}
Acerola (Malpighia emarginata) is a tropical fruit native from Central America and north of South America. It has shown an increasing economic and social importance due to its high vitamin $\mathrm{C}$ (ascorbic acid) content. Vegetative propagation is the preferable method used to establish acerola plantations. However, propagation by seeds has also been used allowing the identification and selection of genotypes that carry characteristics of agronomic interest. Twenty-four acerola accesses, of the Active Germplasm Bank of the Universidade Estadual de Londrina, were analyzed using molecular markers obtained with random amplified polymorphic DNA (RAPD) and simple sequence repeated (SSRs) primers. A total of 164 and 73 markers were obtained with RAPD and SSR primers, respectively. Polymorfic markers were scored as present or absent and analyzed using the UPGMA cluster analysis. The results presented reveal high levels of polymorphism in the studied collection. Comparative analysis of the phenograms, generated with both RAPD and SSR primers, revealed that while some accesses clustered in different groups other accesses presented the same association. However, there was large RAPD variation among the accesses. The associations observed with molecular markers were, for many accesses, the same of those determined on the basis of morphological characters.
\end{abstract}

Index terms: Acerola, Malpighia emarginata, RAPD and SSR markers, genetic variability.

\section{INTRODUÇÃO}

A acerola (Malpighia emarginata) é uma planta típica de países de clima tropical, com seu centro de origem na região do Mar das Antilhas, Norte da América do Sul e América Central. A classificação botânica da acerola tem sido controvertida e, apesar da adoção do nome Malpighia emarginata D.C. pelo Conselho Internacional de Recursos Genéticos Vegetais em 1986, essa denominação ainda é pouco utilizada (Alves \& Menezes, 1995). No Brasil, a acerola é conhecida há mais de 50 anos. Porém, somente no início dos anos 80 , a cultura mostrou uma expansão considerável da área de cultivo, devido ao interesse comercial pelos seus frutos que concentram alto teor de ácido ascórbico (Neto et al., 1995).

A inexistência de variedades definidas de acerola no Brasil é um dos principais fatores que, aliados ao plantio de mudas obtidas por sementes, leva à grande desuniformidade na produção anual de frutos por planta. Este fato tem causado sérias dificuldades para os produtores, gerando perdas na produtividade e na qualidade dos frutos. Em razão disso, a preservação da variabilidade genética da acerola, mediante a constituição de bancos de germoplasma, tem grande importância tanto do ponto de vista da conservação biológica como da aplicação no melhoramento genético.

\footnotetext{
1 (Trabalho 069/2001). Recebido: 23/03/2001. Aceito para publicação: 08/02/2002.

2 Farmacêutica-Bioquímica, Depto. Biologia Geral, Universidade Estadual de Londrina, CEP: 86051-990 Londrina, PR, Brasil.

3 Prof. Associado. Depto. Biologia Geral, Univ. Estadual de Londrina, CEP: 86051-990 Londrina, PR, Brasil

4 Prof. Titular. Depto. Biologia Geral, CCB. Univ. Estadual de Londrina, CEP: 86051-990 Londrina, PR, Brasil

5 Prof. Associado. Depto. de Agronomia, CCA. Univ. Estadual de Londrina, CEP: 86051-990 Londrina, PR, Brasil
} 
As pesquisas genéticas com acerola baseiam-se em caracteres agronômicos e marcadores morfológicos (CarpentieriPípolo et al., 2000 a, b; Gomes et al., 2000). No entanto, estes marcadores existem em número limitado, e sua expressão gênica pode estar sujeita às variações do ambiente. Marcadores moleculares têm sido usados com sucesso na análise genética de plantas e na caracterização da variabilidade contida em bancos de germoplasma. Caracterização de clones de acerola foi realizada por Freitas et al. (1995) com os sistemas isoenzimáticos peroxidase-esterase. Os resultados demonstraram que é possível, por esta metodologia, diferenciar os clones e identificá-los entre si. Porém, quando a investigação requer uma cobertura mais ampla do genoma, o uso de marcadores isoenzimáticos é limitado, uma vez que poucos sistemas isoenzimáticos polimórficos, geralmente entre 10 e 20, podem ser vizualizados em cada espécie (Ferreira e Grattapaglia, 1995).

Nos últimos dez anos, técnicas que permitem fazer distinção diretamente a nível de DNA têm permitido acessar a variabilidade genética dentro do pool gênico de espécies cultivadas, assim como identificar a diversidade disponível em bancos de germoplasma. Os marcadores de DNA apresentam vantagens em relação aos marcadores isoenzimáticos, uma vez que podem ser obtidos em grande número e não sofrem influência de fatores ambientais (Borém, 1998). Wesh e McClelland (1990) e Williams et al. (1990) introduziram uma técnica que se baseia na detecção de polimorfismo de DNA amplificado ao acaso (RAPD), usando oligonucleotídios de dez bases. Esta técnica tem se mostrado eficiente na identificação da variabilidade genética em diversos grupos de plantas e pode ser usada como uma ferramenta auxiliar em programas de melhoramento, encontrando também aplicação na obtenção de mapas genéticos (Williams et al., 1990; Reiter et al., 1992; Philipp et al., 1994; Paillard et al., 1996) e identificação de marcadores moleculares úteis na seleção assistida (Michelmore et al., 1991; Ohmore et al., 1995; Tartarini, 1996) entre outras. Marcadores RAPD foram usados para acessar a variabilidade genética contida em coleções de milho (Welsh et al., 1991), rosa (Gallego \& Martinez, 1996), centeio (Huff, 1997), sorgo (Menkir et al., 1997) e arroz (Fuentes et al., 1999). Poucos exemplos do uso de RAPD têm sido mostrados na literatura em frutíferas. Usando marcadores RAPD, foi possível distinguir entre populações de cacau (Theobroma cacao L.) (Russell et al., 1993) e entre cultivares de castanha (Galderisi et al., 1998). Dunemann et al. (1994), aplicando marcadores RAPD no gênero Malus (maçã), para avaliar as relações genéticas entre 18 espécies e 27 cultivares de maçã, consideraram que a técnica tem potencial para complementar estudos taxonômicos clássicos no gênero.

Técnicas que fazem uso da reação em cadeia da polimerase (PCR), têm acelerado o desenvolvimento de novos sistemas para obtenção de marcadores de DNA, tal como microssatélites ou SSRs (Simple Sequence Repeats). Estes marcadores consistem de seqüências curtas de nucleotídeos repetidas na mesma ordem, cujo nível de polimorfismo produzido é devido à variação no número de unidades de repetição em um determinado lócus (Morgante e Olivieri, 1993). Marcadores SSRs são obtidos com o uso de primers que flanqueiam regiões contendo os microssatélites. Os primers para SSR são desenhados a partir do seqüenciamento de fragmentos de DNA, obtidos de bibliotecas genômicas, onde os microssatélites foram previamente localizados. Estes procedimentos são laboriosos e de alto custo, de modo que o uso de SSRs é ainda limitado. No entanto, SSRs têm sido mapeados e usados para análise genética em plantas como milho (Smith et al., 1997), batata (Provan et al., 1996 e Kawchuk et al., 1996) e cítrus (Kijas et al., 1997). A variabilidade genética contida em coleções de Solanum tuberosum (McGregor, 2000), Malus (Gianfranceschi et al., 1998; Hokanson et al., 2001) foi analisada, usando SSRs. Dados de microssatélites, obtidos para o gênero Musa (banana), mostram uma aplicação imediata para análise genética e sugerem que SSRs podem servir de âncora para a construção de um mapa genético básico em banana (Kaemmer et al., 1997). Marcadores SSRs podem também ser obtidos, usando oligonucleotídeos de seqüências simples repetidas como primers na amplificação de DNA por PCR ou, ainda, como sondas em experimentos de hibridação envolvendo DNA genômico, para a detecção de polimorfismo em famílias de DNA repetitivo (Weising et al., 1995). Esta abordagem foi usada para a análise genética em Helianthus (Dehmer, 1998) e Solanum tuberosum (McGregor et al., 2000).

O presente estudo teve por finalidade utilizar marcadores moleculares obtidos por amplificação de DNA via PCR com iniciadores (primers) de RAPD e com primers de seqüências simples repetidas (SSR), para acessar a variabilidade genética contida em 24 genótipos de acerola (M. emarginata).

\section{MATERIAL E MÉTODOS}

Vinte e quatro acessos de acerola (Tabela 1) foram obtidos da coleção formada a partir da seleção de genótipos em pomares comerciais da região Norte do Paraná, mantida no Banco de Germoplasma da Fazenda-Escola da Universidade Estadual de Londrina.

Aproximadamente $50 \mathrm{mg}$ de folhas frescas de até cinco plantas de cada um dos 24 acessos de acerola foram utilizadas para análise de DNA. O procedimento adotado foi adaptado a partir do método de CTAB (Cethyltrimethylammonium Bromide, Sigma), descrita por Doyle \& Doyle (1987), onde o CTAB foi substituído por MATAB (Mixed Alyltrimethylammonium Bromide, Sigma) no tampão de extração. As amostras foram purificadas pela adição de cloreto de sódio $(\mathrm{NaCl}) 5 \mathrm{M}$ à solução de DNA seguida da precipitação com isopropanol. A quantificação foi realizada em um fluorômetro DyNA Quant 20 (Hoefer-Pharmacia), conforme as especificações do fabricante. Após diluição do DNA para uma concentração de $15 \mathrm{ng} / \mu \mathrm{L}$, volumes iguais de amostras individuais foram reunidos em um único bulk por acesso.

As reações de amplificação realizadas com uso de iniciadores (primers) de RAPD foram feitas em um volume final de $15 \mu \mathrm{L}$, contendo $7,92 \mu \mathrm{L}$ de água estéril; $1,5 \mu \mathrm{L}$ de tampão de amplificação ( $\mathrm{KCl} 50 \mathrm{mM}, \mathrm{MgCl}_{2} 15 \mathrm{mM}$, Tris-Cl 100mM, pH 9,0); $1,5 \mu \mathrm{L}$ de dNTPs ( $0,1 \mathrm{mM}$ de cada dGTP, dATP, dCTP, dTTP); 2 $\mu \mathrm{L}$ de primer (4 mM) da Operon Technologies; $1 \mathrm{U}$ de Taq DNA polimerase (Pharmacia) e 30 ng de DNA. Para as reações com os primers de seqüências simples repetidas (SSR), o volume final foi ajustado a $25 \mu \mathrm{L}$, contendo $9,70 \mu \mathrm{L}$ de água estéril; $1,5 \mu \mathrm{L}$ de glicerol (40\%); $2,5 \mu \mathrm{L}$ de tampão de amplificação ( $\mathrm{KCl} 50 \mathrm{mM}$, $\mathrm{MgCl}_{2} 15 \mathrm{mM}$, Tris-Cl $100 \mathrm{mM}, \mathrm{pH}$ 9,0); 2,5 $\mu \mathrm{l}$ de dNTPs $(0,1 \mathrm{mM}$ de cada dGTP, dATP, dCTP, dTTP); $2,5 \mu \mathrm{L}$ de primer $(4 \mathrm{mM})$ da Operon Technologies; 1,8 U de Taq DNA polimerase (Pharmacia) 
e $3 \mu \mathrm{L}$ (45 ng) de DNA. As reações de amplificação foram conduzidas em um ciclador térmico PTC-100, sistema Peltier (MJ Research) para 60 tubos. O programa de amplificação para as reações com os primers de RAPD consistiu de uma denaturação inicial do DNA a $94^{\circ} \mathrm{C}$ por 4 min, seguido de 48 ciclos que inclui 60 seg a $94^{\circ} \mathrm{C}$ (denaturação), 1 min e 45 s. a $38^{\circ} \mathrm{C}$ (anelamento), 2 min a $72^{\circ} \mathrm{C}$ (polimerização) seguido de uma extensão final de 7 min a $72^{\circ} \mathrm{C}$. Nas reações utilizando primers de SSR, o programa utilizado inclui uma denaturação inicial do DNA a $94^{\circ} \mathrm{C}$ por $4 \mathrm{~min}$, seguido de 40 ciclos de $15 \mathrm{~s}$. a $94^{\circ} \mathrm{C}$ (denaturação), $45 \mathrm{~s}$. a $50^{\circ} \mathrm{C}$ (anelamento), 1 s. a $72^{\circ} \mathrm{C}$ e uma extensão final de 7 min a $72^{\circ} \mathrm{C}$. Os produtos de amplificação foram separados por eletroforese em gel de agarose (Metaphor), corado com brometo de etídio e visualizado sob luz UV.

Os marcadores obtidos foram analisados com o software NTSYS-PC (Numerical Taxonomy and Multivariate Analysis System for personal computers, Version 2.1, Applied Biostatistics, Inc.). A partir dos dados, foi construída uma matriz de similaridade genética, utilizando o coeficiente de Jaccard (J), calculado de acordo com a fórmula: $\mathrm{J}=\mathrm{N} / \mathrm{P}$, onde $\mathrm{N}$ é o número de concordâncias positivas e $\mathrm{P}$ é o número total de variáveis, menos as concordâncias positivas. Para a construção dos dendrogramas, foi utilizado o método de agrupamento UPGMA (Unweighted Pair Group Method with Arithmetic Average).

\section{RESULTADOS E DISCUSSÃO}

\section{Marcadores de RAPD}

Inicialmente, foram utilizadas amostras de DNA de três acessos com o objetivo de selecionar os primers mais informativos. De 94 primers testados, 37 forneceram produtos nítidos de amplificação e boa repetibilidade. Um total de 164 marcadores foram amplificados, com uma média de 4 bandas por primer. Os produtos de amplificação foram utilizados para o cálculo do grau de similaridade genética entre os acessos (Tabela 1). $\mathrm{O}$ padrão eletroforético obtido com primers de RAPD é ilustrado na Figura 1. O número de bandas polimórficas foi $149(90,8 \%)$ e variou de uma, com os primers OPAF-20, OPAE-03 e OPAX-07, a sete, com os primers OPO-08 e OPAR-19.

\section{Análise genética dos marcadores RAPD}

O alto grau de polimorfismo detectado com os marcadores de RAPD está de acordo com a variabilidade observada com base em caracteres morfológicos e agronômicos em acerola (Carpentieri-Pípolo, 2000 a, b; Gomes et al., 2000). Além disso, a variabilidade detectada com marcadores de DNA concorda igualmente com as informações existentes sobre a origem dos genótipos de acerola cultivados no Brasil. Considerase que estes genótipos derivam de poucas sementes trazidas de Porto Rico e multiplicadas por via sexuada (Couceiro, 1985). No entanto, apesar de ter uma base genética estreita, uma elevada segregação genética pode ainda ser observada em pomares onde sementes são intensamente utilizadas na produção de mudas (Carvalho, 1998).

A análise da matriz de similaridade genética e do dendrograma (Tabela 3, Figura 2) permitiu identificar cinco grupos distintos entre os 24 acessos de acerola. Alguns grupos reuniram acessos que compartilham características químicas e morfológicas. O grupo 1 associa oito acessos com coeficientes de similaridade que variam de $65 \%$ a $87 \%$. Entre estes, encontramse associados os acessos UEL-9 e UEL-28, que apresentam a mesma taxa de germinação (49 \%) e os acessos UEL-26 e Iapar-1, os quais apresentam como principal característica, concentrações similares de vitamina C, isto é, $859 \mathrm{mg}$ e $669 \mathrm{mg}$, por $100 \mathrm{~g}$ de polpa, respectivamente (Carpentieri-Pípolo, 2000b). Os acessos UEL-6 e UEL- 10 (grupo 4) associam-se com 79\% de similaridade e mostram, em média, uma concentração de vitamina $C$ de 1470 $\mathrm{mg}$ por $100 \mathrm{~g}$ de polpa (Carpentieri-Pípolo, 2000b). O maior e o menor grau de similaridade genética foram observados entre os acessos UEL-08 e UEL-33 (95\%) e entre Iapar-12 e UEL-06 (57\%), respectivamente. Iapar-12 e UEL-06 foram introduzidos na coleção de acerola a partir de coletas realizadas em pomares implantados em diferentes regiões do Norte do Paraná. Iapar 12 foi mais distinto entre todos os acessos analisados, mostrando uma similaridade média de $67 \%$ com os 23 genótipos restantes. Baixa similaridade genética foi igualmente observada entre alguns acessos procedentes da mesma região. Por exemplo, UEL-32 e UEL-27 foram obtidos de pomares da região de Astorga-PR, e mostram apenas $66 \%$ de similaridade. Da mesma forma, Iapar-06 e Iapar-03, ambos procedentes de Bandeirantes-PR, apresentam somente $76 \%$ de similaridade. Estes resultados sugerem que genótipos distintos têm sido utilizados na implantação dos pomares de acerola. Yee et al. (1999), analisando acessos de Vigna angularia, observaram igualmente ausência de correlação entre grau de similaridade genética obtida com base em marcadores de DNA e procedência dos acessos. Neste caso, os autores apontam para a possibilidade de que a origem dos acessos difere do local de coleta.

As cultivares UEL-03 Dominga, UEL-04 Lígia e UEL-05 Natália, lançadas como variedades comerciais no Brasil (Carpentieri-Pipolo et al., 2000a), foram incluídas neste estudo. Essas variedades compartilham características de interesse agronômico tais como, alta concentração de vitamina $\mathrm{C}$ em seus frutos, pilosidade em ramos e folhas, ramificação intermediária e boa produtividade. No entanto, a similaridade genética média observada com os marcadores RAPD entre as três cultivares foi baixa $(76 \%)$. A diferença genética observada entre acessos que possuem várias características em comum, pode ser explicada considerando que, na reação de RAPD, a mudança de um único nucleotídeo pode levar a uma variação no padrão de bandas obtidos sem que isto altere características morfológicas e químicas. Além disso, de acordo com Irwin et al. (1998), os marcadores de RAPD tendem a se localizar em regiões genômicas não codificantes, mais suscetíveis a mutações e, conseqüentemente, mais polimórficas.

Os acessos UEL-3 Dominga e Iapar-6 aparecem no grupo 3 , associando-se com $80 \%$ de similaridade. Este resultado está de acordo com os dados obtidos por Carpentieri-Pípolo et al. (2000a), onde os acessos UEL-3 Dominga, Iapar-6 e UEL-10 foram avaliados quanto a nove caracteres agronômicos por meio da análise multivariada, e incluídos em um mesmo grupo. No entanto, os marcadores RAPD separam UEL-10 de UEL-3 Dominga e Iapar6 com os quais mostra uma relação de similaridade de $78 \%$ e $72 \%$, respectivamente. Em geral, a variabilidade genética detectada a partir dos marcadores RAPD entre os acessos de acerola pode ser atribuída à intensa utilização de sementes na produção de mudas (Carvalho, 1998), o que leva a uma elevada segregação 
TABELA 1 - Procedência, número de coleção e códigos utilizados pelo Banco Ativo de Germoplasma da Universidade Estadual de Londrina na identificação dos 24 acessos de acerola (M. emarginata D. C.).

\begin{tabular}{|c|c|c|c|}
\hline $\mathrm{N}^{\circ} / \mathrm{Código}$ & Procedência & $\mathrm{N}^{\circ} / \mathrm{C}$ ódigo & Procedência \\
\hline $1 / \mathrm{U}$ EL -12 & A s torga - PR & $13 / \mathrm{UE} \mathrm{L}-3$ & A storga - PR \\
\hline $2 /$ I a p a r -1 & A storga - PR & $14 / \mathrm{U}$ E L -15 & A storga - PR \\
\hline $3 / \mathrm{UEL}-26$ & A storga - PR & $15 / \mathrm{U}$ E L -31 & A storga - PR \\
\hline 4/U E L - 28 & A s torga - PR & $16 / \mathrm{U}$ E L -20 & A storga - PR \\
\hline $5 / \mathrm{UEL}-7$ & A storga - PR & $17 / \mathrm{U} \mathrm{E} \mathrm{L}-11$ & A storga $-P R$ \\
\hline $6 / \mathrm{U}$ EL -5 & A storga - PR & $18 / \mathrm{U} \mathrm{E} \mathrm{L}-33$ & A storga $-P R$ \\
\hline $7 / \mathrm{U}$ E L - 4 & A s torga - PR & $19 / \mathrm{U}$ E L -8 & A s torga - PR \\
\hline $8 /$ U E L - 9 & A storga - PR & $20 /$ I a p a r -6 & $\mathrm{~B}$ andeirantes $-P R$ \\
\hline 9/U E L - 27 & A storga - PR & $21 /$ Ia p a r -3 & Bandeirantes $-P R$ \\
\hline $10 / \mathrm{U}$ E L -24 & A storga - PR & $22 / \mathrm{U}$ E L -36 & Londrin a $-P R$ \\
\hline $11 / \mathrm{U}$ E L -6 & A storga - PR & $23 /$ Ia p a r -12 & Bandeirantes $-P R$ \\
\hline $12 / \mathrm{U}$ E L -10 & A storga - PR & 24 / U E L - 32 & A storga $-P R$ \\
\hline
\end{tabular}

TABELA 2 - Relação dos primers de seqüências simples repetidas (SSRs) utilizados considerando o número de fragmentos totais e polimórficos.

\begin{tabular}{|c|c|c|}
\hline Primer & $\begin{array}{c}\text { Númerototal } \\
\text { de bandas }\end{array}$ & $\begin{array}{c}\text { Númerode bandas } \\
\text { polimórficas }\end{array}$ \\
\hline$\overline{\mathrm{GA}_{9} \mathrm{C}}$ & 05 & 04 \\
\hline $\mathrm{CA}_{5}$ & 04 & 01 \\
\hline $\mathrm{GA} \mathrm{TA}_{4}$ & 05 & 04 \\
\hline $\mathrm{A} \mathrm{G}_{9}$ & 06 & 05 \\
\hline $\mathrm{T} \mathrm{C}_{9}$ & 04 & 02 \\
\hline $\mathrm{CAC}_{6}$ & 04 & 03 \\
\hline $\mathrm{GA}_{9} \mathrm{C} / \mathrm{CA} \mathrm{A}_{5}$ & 05 & 03 \\
\hline $\mathrm{GA}_{9} \mathrm{C} / \mathrm{GA}_{9} \mathrm{~T}$ & 05 & 05 \\
\hline $\mathrm{C} \mathrm{A} \mathrm{G} 5_{5} / \mathrm{A} \mathrm{G}_{9}$ & 05 & 03 \\
\hline $\mathrm{CAG}_{5} / \mathrm{GACA}_{4}$ & 03 & 00 \\
\hline $\mathrm{CA} \mathrm{G}_{5} / \mathrm{GATA}_{4}$ & 06 & 03 \\
\hline $\mathrm{CA} \mathrm{G}_{5} / \mathrm{GA}_{9}$ & 04 & 03 \\
\hline $\mathrm{G} \mathrm{A}_{9} \mathrm{~T} / \mathrm{A} \mathrm{T}_{9}$ & 05 & 02 \\
\hline $\mathrm{GA}_{9} \mathrm{~T} / \mathrm{GA} \mathrm{AA}_{4}$ & 03 & 01 \\
\hline $\mathrm{GATA}_{4} / \mathrm{GACA}_{4}$ & 04 & 03 \\
\hline GA T A $4 / \mathrm{A} \mathrm{G}_{9}$ & 05 & 03 \\
\hline
\end{tabular}

genética. Além disso, a presença em acerola de um sistema genético de auto-incompatibilidade, favorece a polinização cruzada (Neto et al., 1995) e, conseqüentemente, o fluxo gênico entre genótipos distintos, justificando, portanto, o alto polimorfismo encontrado.

\section{Marcadores de SSR}

O uso de primers SSR em reações de PCR possibilita a amplificação de fragmentos de DNA, contidos entre regiões de DNA repetitivo, representadas por seqüências simples repetidas (SSRs) ou microssatélites. Entre os 30 primers SSR testados, 16 (Tabela 2) produziram bandas nítidas e de boa repetibilidade. Um exemplo do padrão eletroforético obtido com primers SSR é apresentado na Figura 1. Combinações entre diferentes primers SSR foram utilizadas na mesma reação, resultando em produtos de amplificação diferentes daqueles obtidos com cada primer usado isoladamente. Um total de 73 marcadores foram analisados, sendo 49 (68\%) polimórficos. Estes marcadores foram utilizados para gerar uma matriz de similaridade genética (Tabela 4) calculada a partir do coeficiente de similaridade de Jaccard.

\section{Análise genética dos marcadores SSR}

$\mathrm{O}$ agrupamento gerado a partir dos marcadores obtidos com os primers SSR mostram a formação de quatro grupos distintos (Figura 3) e um nível de polimorfismo inferior àquele detectado com marcadores RAPD.

A análise comparativa dos dois dendrogramas revelou algumas associações diferentes entre os acessos. Uma similaridade genética de 95\% e 79\% entre os genótipos UEL-26 e UEL-28 e de $91 \%$ e $79 \%$ entre os acessos UEL-06 e UEL-10 foi 
TABELA 3 - Similaridade genética observada entre 24 genótipos de M. emarginata a partir de marcadores RAPD.

\begin{tabular}{|c|c|c|c|c|c|c|c|c|c|c|c|c|c|c|c|c|c|c|c|c|c|c|c|c|}
\hline acessos & 1 & 2 & 3 & 4 & 5 & 6 & 7 & 8 & 9 & 10 & 11 & 12 & 13 & 14 & 1 & 16 & 17 & 18 & 19 & 20 & 21 & 22 & 23 & 24 \\
\hline 1. Uel-12 & 1.00 & & & & & & & & & & & & & & & & & & & & & & & \\
\hline 2. Iapar-1 & 0.82 & 1.00 & & & & & & & & & & & & & & & & & & & & & & \\
\hline 3. Uel-26 & 0.81 & 0.87 & 1.00 & & & & & & & & & & & & & & & & & & & & & \\
\hline 4. Uel-28 & 0.79 & 0.76 & 0.79 & 1.00 & & & & & & & & & & & & & & & & & & & & \\
\hline 5. Uel-7 & 0.85 & 0.86 & 0.83 & 0.81 & 1.00 & & & & & & & & & & & & & & & & & & & \\
\hline 6. Uel-5 & 0.80 & 0.82 & 0.81 & 0.79 & 0.87 & 1.00 & & & & & & & & & & & & & & & & & & \\
\hline 7. Uel-4 & 0.75 & 0.81 & 0.75 & 0.78 & 0.78 & 0.75 & 1.00 & & & & & & & & & & & & & & & & & \\
\hline 8. Uel-9 & 0.77 & 0.78 & 0.76 & 0.73 & 0.76 & 0.71 & 0.74 & 1.00 & & & & & & & & & & & & & & & & \\
\hline 9. Uel-27 & 0.70 & 0.76 & 0.70 & 0.78 & 0.76 & 0.74 & 0.75 & 0.71 & 1.00 & & & & & & & & & & & & & & & \\
\hline 10. Uel-24 & 0.72 & 0.76 & 0.69 & 0.75 & 0.76 & 0.70 & 0.79 & 0.74 & 0.78 & 1.00 & & & & & & & & & & & & & & \\
\hline 11. Uel-6 & 0.73 & 0.75 & 0.73 & 0.72 & 0.81 & 0.75 & 0.76 & 0.70 & 0.78 & 0.79 & 1.00 & & & & & & & & & & & & & \\
\hline 12. Uel-10 & 0.76 & 0.79 & 0.78 & 0.72 & 0.76 & 0.76 & 0.72 & 0.75 & 0.76 & 0.79 & 0.79 & 1.00 & & & & & & & & & & & & \\
\hline 13. Uel-3 & 0.72 & 0.75 & 0.68 & 0.70 & 0.75 & 0.76 & 0.79 & 0.67 & 0.72 & 0.73 & 0.78 & 0.78 & 1.00 & & & & & & & & & & & \\
\hline 14. Uel-15 & 0.76 & 0.77 & 0.75 & 0.74 & 0.74 & 0.72 & 0.72 & 0.71 & 0.72 & 0.72 & 0.70 & 0.74 & 0.72 & 1.00 & & & & & & & & & & \\
\hline 15. Uel-31 & 0.68 & 0.72 & 0.70 & 0.74 & 0.70 & 0.67 & 0.79 & 0.71 & 0.72 & 0.77 & 0.75 & 0.70 & 0.73 & 0.74 & 1.00 & & & & & & & & & \\
\hline 16. Uel-20 & 0.81 & 0.81 & 0.81 & 0.78 & 0.83 & 0.83 & 0.81 & 0.73 & 0.73 & 0.75 & 0.76 & 0.79 & 0.84 & 0.77 & 0.78 & 1.00 & & & & & & & & \\
\hline 17. Uel-11 & 0.82 & 0.83 & 0.81 & 0.75 & 0.78 & 0.75 & 0.76 & 0.76 & 0.75 & 0.71 & 0.68 & 0.78 & 0.69 & 0.78 & 0.69 & 0.81 & 1.00 & & & & & & & \\
\hline 18. Uel-33 & 0.78 & 0.81 & 0.75 & 0.71 & 0.73 & 0.71 & 0.76 & 0.73 & 0.67 & 0.70 & 0.69 & 0.76 & 0.73 & 0.75 & 0.73 & 0.75 & 0.76 & 1.00 & & & & & & \\
\hline 19. Uel-8 & 0.79 & 0.82 & 0.75 & 0.71 & 0.72 & 0.71 & 0.75 & 0.73 & 0.67 & 0.68 & 0.68 & 0.73 & 0.72 & 0.77 & 0.71 & 0.75 & 0.76 & 0.98 & 1.00 & & & & & \\
\hline 20. Iapar-6 & 0.70 & 0.73 & 0.71 & 0.70 & 0.70 & 0.65 & 0.78 & 0.67 & 0.73 & 0.76 & 0.72 & 0.72 & 0.80 & 0.75 & 0.85 & 0.77 & 0.68 & 0.77 & 0.76 & 1.00 & & & & \\
\hline 21. Iapar-3 & 0.70 & 0.73 & 0.70 & 0.70 & 0.73 & 0.68 & 0.70 & 0.65 & 0.76 & 0.70 & 0.73 & 0.72 & 0.78 & 0.71 & 0.70 & 0.76 & 0.73 & 0.74 & 0.72 & 0.76 & 1.00 & & & \\
\hline 22. Uel-36 & 0.76 & 0.80 & 0.76 & 0.68 & 0.72 & 0.71 & 0.70 & 0.74 & 0.68 & 0.70 & 0.69 & 0.75 & 0.77 & 0.75 & 0.71 & 0.76 & 0.79 & 0.76 & 0.76 & 0.72 & 0.76 & 1.00 & & \\
\hline 23. Iapar-12 & 0.73 & 0.75 & 0.72 & 0.73 & 0.68 & 0.68 & 0.70 & 0.71 & 0.65 & 0.64 & 0.57 & 0.67 & 0.65 & 0.74 & 0.65 & 0.72 & 0.70 & 0.76 & 0.79 & 0.68 & 0.70 & 0.75 & 1.00 & \\
\hline 24. Uel-32 & 0.71 & 0.73 & 0.72 & 0.71 & 0.67 & 0.68 & 0.74 & 0.67 & 0.66 & 0.70 & 0.65 & 0.71 & 0.73 & 0.70 & 0.75 & 0.79 & 0.76 & 0.73 & 0.72 & 0.72 & 0.74 & 0.81 & 0.70 & 1.00 \\
\hline
\end{tabular}

TABELA 4 - Similaridade genética observada entre 24 acessos de M. emarginata utilizando marcadores de DNA obtidos com primers de seqüências simples repetidas

\begin{tabular}{|c|c|c|c|c|c|c|c|c|c|c|c|c|c|c|c|c|c|c|c|c|c|c|c|c|}
\hline acessos & 1 & 2 & 3 & 4 & 5 & 6 & 7 & 8 & 9 & 10 & 11 & 12 & 13 & 14 & 15 & 16 & 17 & 18 & 19 & 20 & 21 & 22 & 23 & 24 \\
\hline 1. Uel-12 & 1.00 & & & & & & & & & & & & & & & & & & & & & & & \\
\hline 2. Iapar-1 & 0.84 & 1.00 & & & & & & & & & & & & & & & & & & & & & & \\
\hline 3. Uel-26 & 0.90 & 0.89 & 1.00 & & & & & & & & & & & & & & & & & & & & & \\
\hline 4. Uel-28 & 0.89 & 0.84 & 0.95 & 1.00 & & & & & & & & & & & & & & & & & & & & \\
\hline 5. Uel-7 & 0.94 & 0.79 & 0.84 & 0.83 & 1.00 & & & & & & & & & & & & & & & & & & & \\
\hline 6. Uel-5 & 0.89 & 0.76 & 0.87 & 0.86 & 0.89 & 1.00 & & & & & & & & & & & & & & & & & & \\
\hline 7. Uel-4 & 0.86 & 0.82 & 0.90 & 0.91 & 0.80 & 0.91 & 1.00 & & & & & & & & & & & & & & & & & \\
\hline 8. Uel-9 & 0.84 & 0.78 & 0.89 & 0.87 & 0.82 & 0.90 & 0.87 & 1.00 & & & & & & & & & & & & & & & & \\
\hline 9. Uel-27 & 0.79 & 0.72 & 0.78 & 0.76 & 0.82 & 0.79 & 0.71 & 0.80 & 1.00 & & & & & & & & & & & & & & & \\
\hline 10. Uel-24 & 0.86 & 0.79 & 0.84 & 0.86 & 0.80 & 0.86 & 0.91 & 0.84 & 0.74 & 1.00 & & & & & & & & & & & & & & \\
\hline 11. Uel-6 & 0.86 & 0.82 & 0.87 & 0.83 & 0.83 & 0.83 & 0.86 & 0.82 & 0.82 & 0.86 & 1.00 & & & & & & & & & & & & & \\
\hline 12. Uel-10 & 0.89 & 0.84 & 0.93 & 0.89 & 0.83 & 0.86 & 0.89 & 0.87 & 0.79 & 0.86 & 0.91 & 1.00 & & & & & & & & & & & & \\
\hline 13. Uel-3 & 0.80 & 0.76 & 0.84 & 0.83 & 0.75 & 0.83 & 0.86 & 0.87 & 0.79 & 0.83 & 0.89 & 0.89 & 1.00 & & & & & & & & & & & \\
\hline 14. Uel-15 & 0.89 & 0.76 & 0.87 & 0.86 & 0.89 & 0.86 & 0.83 & 0.79 & 0.74 & 0.83 & 0.78 & 0.83 & 0.75 & 1.00 & & & & & & & & & & \\
\hline 15. Uel-31 & 0.89 & 0.82 & 0.93 & 0.94 & 0.83 & 0.86 & 0.89 & 0.87 & 0.74 & 0.89 & 0.80 & 0.86 & 0.83 & 0.91 & 1.00 & & & & & & & & & \\
\hline 16. Uel-20 & 0.90 & 0.83 & 0.91 & 0.93 & 0.84 & 0.84 & 0.87 & 0.86 & 0.75 & 0.84 & 0.82 & 0.87 & 0.84 & 0.87 & 0.95 & 1.00 & & & & & & & & \\
\hline 17. Uel-11 & 0.93 & 0.83 & 0.91 & 0.93 & 0.87 & 0.84 & 0.90 & 0.83 & 0.72 & 0.84 & 0.84 & 0.90 & 0.82 & 0.90 & 0.93 & 0.94 & 1.00 & & & & & & & \\
\hline 18. Uel-33 & 0.84 & 0.75 & 0.83 & 0.82 & 0.79 & 0.79 & 0.82 & 0.75 & 0.69 & 0.76 & 0.76 & 0.82 & 0.74 & 0.84 & 0.84 & 0.83 & 0.89 & 1.00 & & & & & & \\
\hline 19. Uel-8 & 0.84 & 0.78 & 0.86 & 0.82 & 0.79 & 0.79 & 0.82 & 0.78 & 0.72 & 0.76 & 0.79 & 0.84 & 0.76 & 0.84 & 0.84 & 0.83 & 0.89 & 0.94 & 1.00 & & & & & \\
\hline 20. Iapar-6 & 0.86 & 0.79 & 0.90 & 0.91 & 0.80 & 0.83 & 0.86 & 0.87 & 0.74 & 0.89 & 0.80 & 0.86 & 0.83 & 0.89 & 0.97 & 0.93 & 0.90 & 0.84 & 0.84 & 1.00 & & & & \\
\hline 21. Iapar-3 & 0.83 & 0.79 & 0.90 & 0.86 & 0.78 & 0.80 & 0.80 & 0.84 & 0.79 & 0.83 & 0.86 & 0.86 & 0.86 & 0.83 & 0.89 & 0.84 & 0.82 & 0.76 & 0.79 & 0.89 & 1.00 & & & \\
\hline 22. Uel-36 & 0.84 & 0.78 & 0.86 & 0.84 & 0.82 & 0.79 & 0.82 & 0.75 & 0.75 & 0.76 & 0.82 & 0.82 & 0.74 & 0.79 & 0.82 & 0.83 & 0.86 & 0.83 & 0.83 & 0.79 & 0.76 & 1.00 & & \\
\hline 23. Iapar-12 & 0.78 & 0.74 & 0.82 & 0.80 & 0.72 & 0.72 & 0.78 & 0.76 & 0.65 & 0.75 & 0.78 & 0.86 & 0.78 & 0.72 & 0.78 & 0.82 & 0.82 & 0.71 & 0.74 & 0.78 & 0.78 & 0.79 & 1.00 & \\
\hline 24. Uel-32 & 0.86 & 0.84 & 0.90 & 0.86 & 0.80 & 0.83 & 0.89 & 0.82 & 0.74 & 0.83 & 0.86 & 0.89 & 0.80 & 0.80 & 0.83 & 0.84 & 0.87 & 0.79 & 0.82 & 0.80 & 0.83 & 0.87 & 0.80 & 1.00 \\
\hline
\end{tabular}




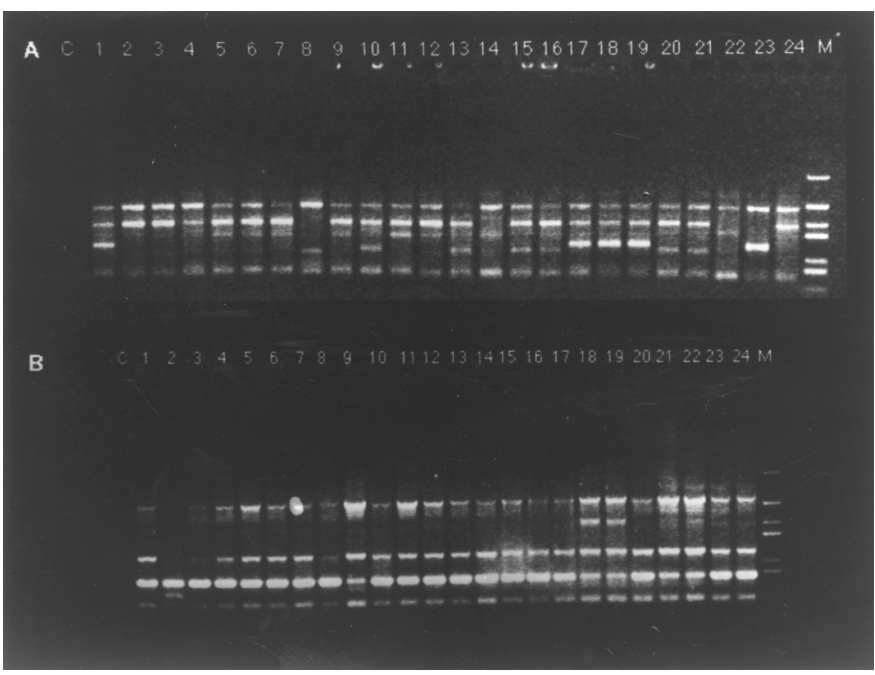

FIGURA 1 - Padrão eletroforético obtido pela amplificação do DNA em 24 genótipos de Malpighia emarginata utilizando A: primer de RAPD OPAR-2 e B: primer de microssatélites $\mathrm{GA}_{9} \mathrm{C}$. Os acessos estão numerados de acordo com as Tabelas 1 e 2. C: amostra-controle. M: Puc 19, marcador de peso molecular com fragmentos de tamanhos em kilobase $(\mathrm{kb})$ e em ordem decrescente iguais a: 2,$7 ; 2,0 ; 1,6 ; 1,4 ; 1,0 ; 0,7 ; 0,5$ e 0,4 .

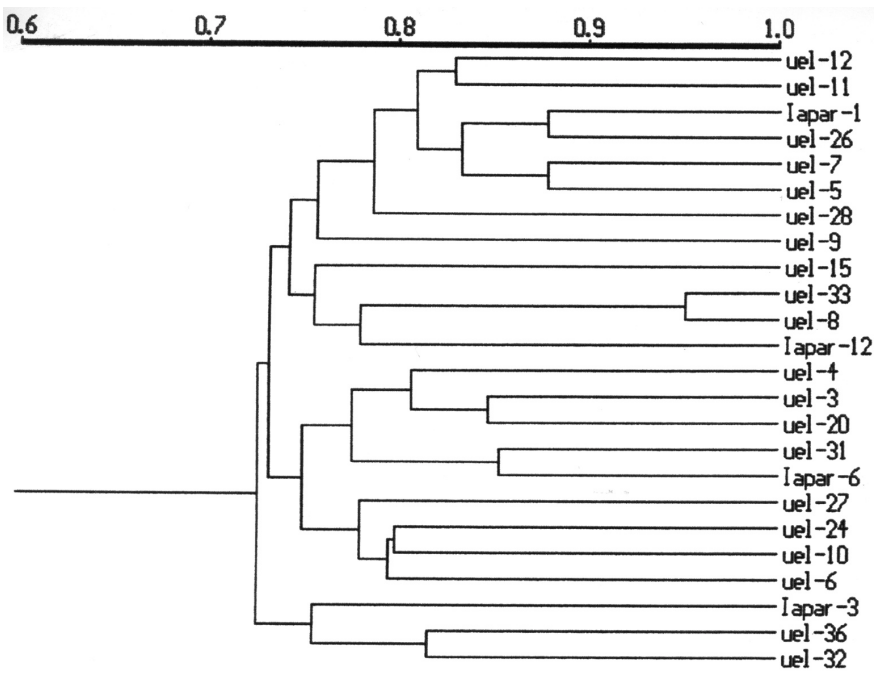

FIGURA 2 - Dendrograma de 24 genótipos de acerola, construído a partir dos produtos de amplificação obtidos com os primers de RAPD, usando o método de agrupamentos UPGMA.

observada com marcadores SSR e RAPD, respectivamente. Estes resultados discordam daqueles mostrados para o gênero Microseris (Van Heusden \& Bachmann, 1996), onde os resultados de RAPD foram similares aos obtidos com primers repetitivos e com isoenzimas. A eficiência na identificação da similaridade genética entre as cultivares UEL-03 Dominga, UEL-04 Lígia e UEL-05 Natália foi também maior (91\%) com os marcadores obtidos com os primers SSR do que com RAPD (76\%), concordando, portanto, com os caracteres morfológicos compartilhados por estas cultivares. Primers SSR foram mais eficientes, em relação aos de RAPD, para a análise genética em trigo (Nagaoka \&

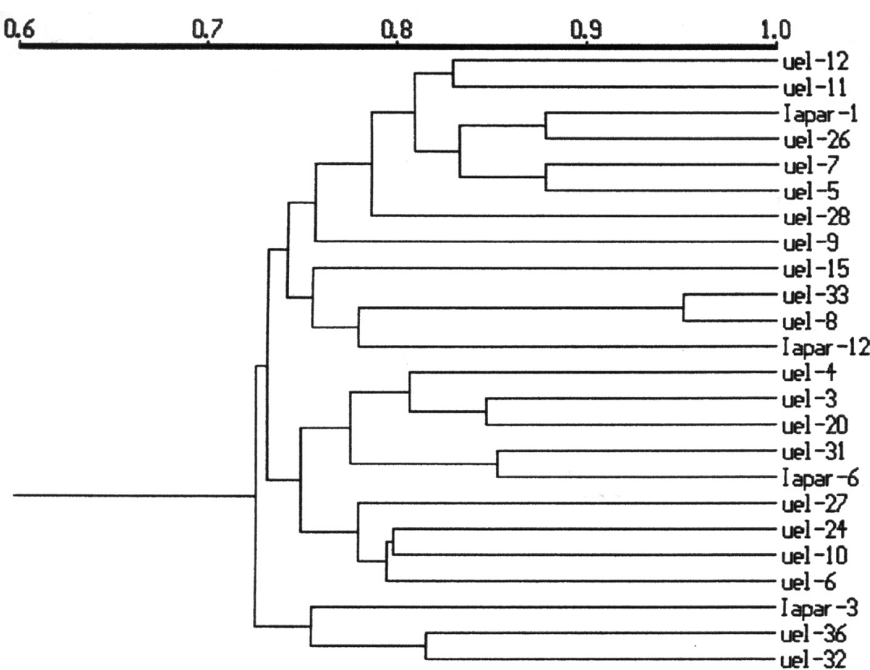

FIGURA 3 - Dendrograma de 24 genótipos de acerola, construído a partir dos produtos de amplificação com os primers de SSR, usando o método de agrupamentos UPGMA.

Ogihara, 1997), produzindo bandas mais nítidas e maior repetibilidade. Por outro lado, Van de Vem \& McNicol (1996) mostraram que primers de RAPD identificaram com maior precisão acessos de Picea sitchensis.

Em alguns casos, as associações encontradas no dendrograma gerado com os dados obtidos com primers SSR foram semelhantes às observadas com RAPD. Por exemplo, os acessos UEL-33 e UEL-08 mostraram elevada similaridade genética tanto com primers de RAPD (95\%) quanto com primers SSR (98\%). O acesso Iapar-12 foi novamente o mais divergente, mostrando uma similaridade que variou de $65 \%$ (RAPD), com o acesso UEL-27, a 80\% (SSR), com o acesso UEL-32.

\section{CONCLUSÕES}

Em geral, o polimorfismo gerado com os marcadores de DNA mostrou que, apesar da base genética estreita, que caracteriza as coleções de acerola encontradas no Brasil, a variabilidade é relativamente alta. Enquanto os marcadores RAPD permitiram detectar maior nível de polimorfismo, a similaridade identificada por marcadores gerados com primers SSR sugere uma maior correlação com associações obtidas a partir de caracteres morfológicos. Em alguns casos, a variação observada foi de difícil interpretação, devido à ausência de uma caracterização morfológica detalhada de muitos dos acessos incluídos neste estudo. Os resultados obtidos a partir de marcadores de DNA podem auxiliar na definição de estratégias mais eficientes a serem utilizadas nos programas de melhoramento de acerola.

\section{REFERÊNCIAS BIBLIOGRÁFICAS}

ALVES, R. E. \& MENEZES, J. B. Botânica da aceroleira. In: SÃO JOSÉ, A. R. \& ALVES, R. E. ed. Acerola no Brasil: Produção e Mercado. Vitória da Conquista-BA, UESB, p.7-14, 1995. 
BORÉM, A. Melhoramento de Plantas. 2. ed. Universidade Federal de Viçosa, 453p., 1998.

CARPENTIERI-PÍPOLO, V. C.; PRETE, C. E. C.; GONZÁLES, M. G. N.; POPPER, I. O. Acerola UEL-3 Dominga, Acerola UEL-4 Lígia, Acerola UEL-5 Natália. In: Novas variedades Brasileiras de frutas, Jaboticabal, Sociedade Brasileira de Fruticultura, 205p., 2000a.

CARPENTIERI-PÍPOLO, V. C.; DESTRO, D.; PRETE, C. E. C.; GONZÁLES, M. G. N.; POPPER, I. O.; ZANATA, S.; SILVA, F. A. M. Seleção de genótipos parentais de acerola baseada na divergência genética multivariada. Pesquisa Agropecuária Brasileira, v. 35, n. 8, p. 341-345, 2000b.

CARVALHO, R. I. N. Variabilidade em plantas jovens de aceroleira propagadas por semente. Agropecuária Catarinense, v. 11, n. 1, p. 16-18. 1998.

COUCEIRO, E. M. Curso de extensão sobre a cultura da acerola. Recife: UFRPE. 45p. 1985.

DEHMER, K. J.; FRIEDT, W. evaluation of different microsatellite motifs for analyzing genetic relationships in cultivated sunflower (Helianthus annuus L.). Plant Breeding, v. 117, p. 45-48. 1998.

DOYLE, J. J.; DOYLE, J. L. A rapid isolation procedure for small quantities of freash leaf tissue. Phytochemical Bulletin, v. 19, p. 11-15. 1987.

DUNEMANN, F.; KAHNAU, R.; SCHMIDT, H. Genetic relationship in Malus evaluated by RAPD fingerprinting of cultivars and wild species. Plant Breeding, v. 113, p. 150-159. 1994.

FERREIRA, M. E.; GRATTAPAGLIA, D. Introdução ao uso de marcadores RAPD e RFLP em Análise Genética. Embrapa, Cenargem, Brasília, DF. 220 pgs. 1995.

FREITAS, N. S. A.; BURITY, H. A.; BEZERRA, J. E. F.; SILVA, M. V. Caracterização de clones de acerola (Malpighia glabra L.) através dos sistemas isoenzimáticos peroxidase-esterase. Pesquisa Agropecuária Brasileira, v. 30, p. 1453-1457. 1995.

FUENTES, J. L.; ESCOBAR, F.; ALVAREZ, A.; GALLEGO, G.; DUQUE, M. C.; FERRER, M.; DEUS, J. E.; TOHME, J. M. Analyses of genetic diversity in Cuban rice varieties using isoenzyme, RAPD and AFLP markers. Euphytica, v. 109, p. 107115. 1999.

GALDERISI, V.; CIPOLLARO, M. G.; MASI, C. B. L.; GALANO, G.; CASCINO, A. Molecular typing of Italian sweet chestnut cultivars by random amplified polymorphic DNA analysis. Journal of Science \& Biotechnology, v. 73, n. 2, p. 259-263. 1998.

GALLEGO, F. J. \& MARTINEZ, I. Molecular typing of rose cultivars using RAPDs. Journal of Horticultural Science, v. 71, n. 6, p. 901-908. 1996.
GIANFRANCESCHI, L.; SEGLIAS, N.; TARCHINI, R.; KOMJANC, M.; GESSLER, C. Simple sequence repeats for genetic analysis of apple. Theoretical and Applied Genetics. v. 96, p. 1069-1076. 1998.

GOMES, J. E.; PERECIN, D.; MARTINS, A. B. G.; FERRAUDO, A. S. Análise de agrupamentos e de componentes principais no processo seletivo em genótipos de aceroleira (Malpighia emarginata D. C.). Revista Brasileira de Fruticultura. v. 22, n. 1, p. 36-39. 2000.

HOKANSON, S. C.; LAMBOY, W. F.; SZEWC-McFADDEN, A. K.; McFERSON, J. R. Microsatellite (SSR) variation in a collection of Malus (apple) species and hybrids. Euphytica, v. 118, p. 281294.2001.

OHMORI, T.; MURATA, M.; MOTOYOSHI, F. Molecular characterization of RAPD and SCAR markers linked to the Tm-1 locus in tomato. Theoretical and Applied Genetics. v. 92, p. 151156. 1996.

HUFF, D. R. RAPD characterization of heterogeneous perennial ryegrass cultivars. Crop Science, v. 37, p. 557-564. 1997.

IRWIN, S. V.; KAUFUSI, P.; BANKS, K.; PEÑA, R. de la; CHO, J. J. Molecular characterization of taro (Colocasia esculenta) using RAPD markers. Euphytica, v.99: p. 183-189. 1998.

KAEMMER, D.; FISCHER, D.; JARRET, R. L.; BAURENS, F.-C.; GRAPIN, A.; DAMBIER, D.; NOYER, J.-L.; LANAUD, C.; KAHL, G.; LAGODA, P. J. L. Molecular breeding in the genus Musa: a strong case for STMS marker technology. Euphytica, v. 96, p. 4963. 1997.

KAWCHUK, L. M.; LYNCH, D. R.; THOMAS, J.; PENNER, B.; SILLITO, D.; KULCSAR, F. Characterization of Solanum tuberosum simple sequence repeats and application to potato cultivar identification. American Potato Journal. v. 73, p. 325 335. 1996.

KIJAS, J. M. H.; THOMAS, M. R.; FOWLER, J. C. S.; ROOSE, M. L. Integration of trinucleotide microsatellites into a linkage map of Citrus. Theoretical and Applied Genetics. v. 94, p. 701-706. 1997.

McGREGOR, C. E.; LAMBERT, C. A.; GREYLING, M. M.; LOUW, J. H.; WARNICH, L. A comparative assessment of DNA fingerprinting techniques (RAPD, ISSR, AFLP and SSR) in tetraploid potato (Solanum tuberosum L.). Euphytica, v. 113, p. 135-144. 2000.

MENKIR, A.; GIELDSBROUGH, P.; EJETA, G. RAPD based assessment of genetic diversity in cultivated races of sorghum. Crop Science, v.37, p. 564-569, 1997.

MICHELMORE, R. W.; PARAN, I.; KESSELI, R. V. Identification of markers linked to disease resistance genes by bulked segregant analysis: A rapid method to detect markers in specific genomic regions by using segregating populations. Proceedings of the 
National Academy of Science. USA. v. 88, p. 9828-9832. 1991.

NAGAOKA, T.; OGIHARA, Y. Applicability of inter-simple sequence polimorphisms in wheat for use as DNA markers in comparison to RFLP and RAPD markers. Theoretical and Applied Genetics, v.94, p.597-602. 1997.

NETO, L. G.; SOARES, M. S.; CHOUDHURY, M. M.; LEAL, I. M. A cultura da acerola. Brasília: Plantar, EMBRAPA - SPI, 101p, 1995.

OLIVEIRA, J. R. P.; SOARES, W. S. F. Acerola: conservação, caracterização e seleção de germoplasma pelo CNPMF EMBRAPA. In: SÃO JOSÉ, A. R. \& ALVES, R. E. Acerola no Brasil: Produção e Mercado. UE Sudoeste BA - Vitória da Conquista-Bahia, p. 22-27. 1995.

PHILIPP, U.; WEHLING, P.; WRICKE, G. A linkage map of rye. Theoretical and Applied Genetics. v. 88, p. 243-238. 1994.

PROVAN, J.; POWELL, W.; WAUGH, R. MIcrosatellite analysis of relationships within cultivated potato (Solanum tuberosum) . Theoretical and Applied Genetics. v. 92, p. 1078-1084. 1996.

REITER, R. S.; WILLIAMS, J. K. G.; FELDMAN, K. A.; RAFALSKI, J. A.; TINGEY, S. V.; SKILNIK, P. A. Global and local genome mapping in Arabidopsis thaliana by using recombinant inbred lines and random amplified polymorphic DNAs. Proceedings of the National Academy of Science. USA. v. 89, p. 1477-1481. 1992.

RUSSELL, J. R.; HOSEIN, F.; JOHNSON, E.; WAUGH, R.; POWELL, W. Genetic differentiation of cocoa (Theobroma cacao L.) populations revealed by RAPD analysis. Molecular Ecology, v. 2, p. 89-97. 1993.

SMITH, J. S. C.; CHIN, E. C. L.; SHU, H.; SMITH, O. S.; WALL,
S. J.; SENIOR, M. L.; MICHELL, S. E.; KRESOVICH, S.; ZIEGLE, $\mathrm{S}$. An evaluation of the utility of ssr loci as molecular markers in maize (Zea mays L.): comparisons with data from RFPS and pedigree. Theoretical and Applied Genetic. v. 95, p. 163-173. 1997.

TARTARINI, S. RAPD markers linked to the $V f$ gene for scab resistance in apple. Theoretical and Applied Genetic. v. 92, p. 803-810. 1996.

VAN HEUSDEN, A. W.; BACHMANN, K. Genotype relationships in Microseris elegans (Asteraceae, Lactuceae) revealed by DNA amplification from arbitrary primers (RAPDs). Plant Systematic Evolution, v.179, p.221-233. 1996.

VAN de VEN, W. T. G.; McNICOL, R. J. Microsatellites as DNA markers in Sitka spruce. Theoretical and Applied Genetics, v.93, p.613-617. 1996.

WELSH, J.; HONEYCUTT, R. J.; McCLELLAND, M.; SOBRAL, B. W. S. Parentage determination in maize hybrids using the arbitrarily primed polymerase chain reaction (AP-PCR). Theoretical and Applied Genetics, v.82, p.473-476. 1991.

WEISING, K.; NYLOM, H.; WOLFF, K.; MEYER, W. DNA Fingerprinting in Plants and Fungi. CRC Press, Boca Raton, Florida. pp. 322. 1995.

WILLIAMS, J. K. G.; KUBELI, K. J.; RAFALSKI, J. A.; TINGEY, S. V. DNA polymorphisms amplified by arbitrary primers are useful as genetic markers. Nucleic Acids Research. v. 18, p. 6531-6535. 1990 .

YEE, E.; KIDWELL, K. K.; SILLS, G. R.; LUMPKIN, T. A. Diversity among selected Vigna angularis (azuki) accessions on the basis of RAPD and AFLP markers. Crop Science, v. 39, p. 268-275. 1999. 